\title{
Intraoral melanoma located at the interproximal mandibular teeth gingiva
}

\author{
Peraza Labrador Alberto*
}

Department of Oral Surgery and Oral Pathology, Pontificia Universidad Javeriana, Carrera 7ma.número 40-62 Bogota-Colombia

\section{Introduction}

Melanomas are malignants neoplasms arising from melanocytes, originating from the neural crest cells, it's account for 1-3\% of all malignants tumors and the incidence is increasing in Western Countries up to 6-7\% yearly [1]. Most of the IntraOral Melanomas had radial growth phases similar to Acral Lentiginous Melanoma (ALM) of the Skin [2]. The frequency of intraoral melanoma among Japanese is higher than that among Caucasians [3]. The most common site for mucosal melanoma is the head and neck region (55\%), followed by the anal/rectal region $(24 \%)$, female genital tract $(18 \%)$, and urinary tract (3\%). Oral melanomas comprise $50 \%$ of head and neck melanomas, and the most frequent site of intraoral melanoma is the palate, followed by maxillary gingiva. In a previous study, mandibular gingival melanomas comprised $7 \%$ of 703 another unusual place of the body that Melanomas shows are the upper aerodigestivetract [4].

Primary intraoral melanoma of the head and neck is a rare entity, occurring much less frequently than its cutaneous relatives. Less than $1 \%$ of all melanomas [5]. Sortino-Rachou et al. reported a total of 124.436 oral cancer and 319 cases of primary oral Melanoma from 67 Cancer registries in five Continents, from 1998 to 2002, the result showed that OMM accounts for $0.26 \%$ of all oral cavity cancers [6]. The most frequently affected oral sites are the palate and maxillary gingiva, that's why some author think that oral melanoma it's a separate entity from its cutaneous counterpart and should be classified separately [7-9].

Intraoral Amelanotic melanoma (IAM) is an extremely rare lesion, comprising $2-8 \%$ of all melanomas 10 . Only 34 cases of oral AM have been reported in the English and Japanese literature until 2011. The sites in those cases were palatal $(n=17)$, maxillary gingiva $(\mathrm{n}=13)$, upper lip mucosa $(\mathrm{n}=1)$, and mandibular gingiva $(\mathrm{n}=2)$. It is difficult to distinguish IAM from other malignant lesions such as undifferentiated carcinoma, fibrosarcoma, or malignant lymphoma [10-14]. Despite aggressive resection and multimodal treatment with added radiotherapy and/or chemotherapy, the median survival is 19 months and the 5 -year overall is $0-20 \%$. 10 There is a research who treat and follow 21 patients with OMM, and the five year of 12 patient survival rate was $91 \%$ with no preoperative surgical procedure, while that of the 9 patients who had undergone surgical procedure before treatment was $26 \%$ [15-17].

Despite of multimodal treatment, prognosis of OMM remains very poor; also because of the rarity of this tumor, there is a lack of definitve proof regarding etiology, pathogenesis, treatment protocol and prognostic factor for OMM [18].

\section{Case report}

A 37 years old woman reported to the Comprehensive Dental Center in Acarigua-Venezuela referred by a general Dentist who saw an unusual type of lesion in the lingual mandibular gingiva of 2 months of evolution, with an insidious onset, and growing in size, the patient had periodontal problems and she received several periodontal treatments before the biopsy, it was asymptomatic, non-ulcerated. She was on healthy condition without any story of Cancer, on examination a nodular single $2 \times 1.5 \mathrm{~cm}$ mass smooth surface indurated with sessile base and surrounded the interproximal distal space between tooth 15 and 16 (first and second left lower molars, no Radiograph evidence of bone compromised) and end with small $5 \mathrm{~mm}$ mass on the buccal interproximal gingiva, grade 1 mobility on molar 15 . The pigmentation was only seen on the lingual area. The Biopsy required to make pull out the first lower molar to take a good sample, who received big blood supply on the lingual area. The lesion was positive for Melanoma level III according with Prassad et al. [19] the patient was sent for Chest $\mathrm{x}$-ray and computer tomography (CT) scan of the cervical area to rule out any metastatic lesion that was negative.

\section{Discussion}

Previous studies show that the male: female ratio of OMM is 1:1.1 to $2: 1$ and the median age is $65-69$ years with a range of $31-91$ years. The peak incidence is at 41-70 years and the lowest incidence it is under 30 years $[4,5,7,11]$. Non-pigmented tumors account for $2.9-5.0 \%$ of total OMMs. The most common primary sites are the hard palate and gingiva (74-80\%); the rarest locations are the buccal mucosa, tongue and floor of the mouth. Lymph node metastasis occurs in $10-54 \%$ patients. The prevalence of distant metastasis is $15-60 \%$ at diagnosis. The lung is the most common metastatic site [7]. For the treatment of 51 patient with OMM, the prognosis in patient younger than 55 years of age at first diagnosis the 3 and 5 years overall survive (OS) were $43.4 \%$ and $21.7 \%$ respectively, whereas they were $19.8 \%$ and $6.6 \%$ in patients more than 55 years of age. This was compared between different clinical features and different therapies. The patients who received biotherapy had better survival rates ( 3 years OS and 5 years OS $70.1 \%$ and $58.4 \%$ respectively) than those who did not receive biotherapy (25\% and $12.5 \%)$ Similarly, TanyN1M0 patients who

Correspondence to: Peraza Labrador Alberto, Department of Oral Pathology, Pontificia Universidad Javeriana, Carrera 7ma.número 40-62, Bogota-Colombia, Tel: 0057-3016588670, E-mail: alberflamen57@hotmail.com

Received: August 08, 2015; Accepted: September 15, 2015; Published: September 18, 2015 


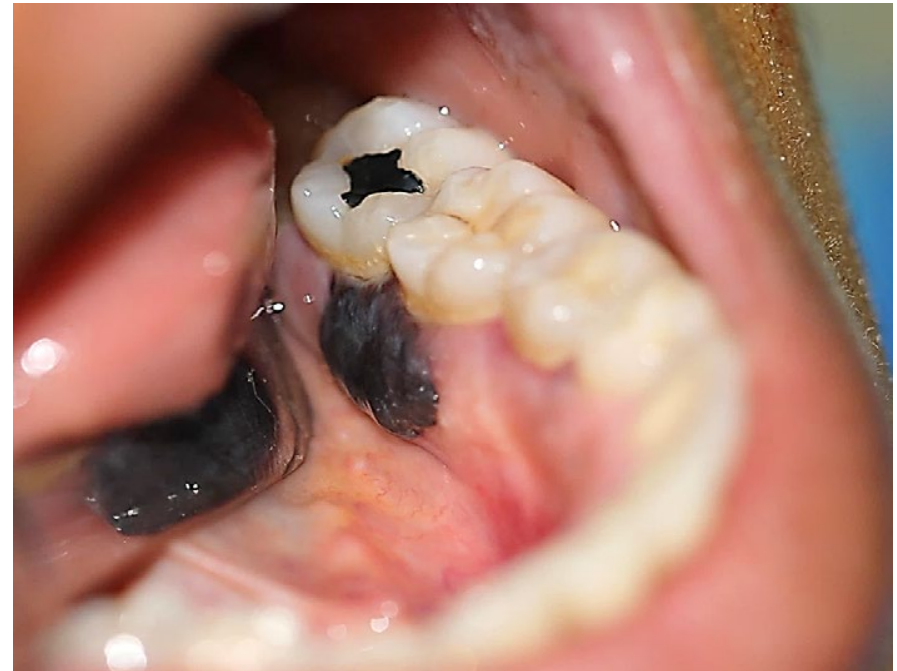

Figure 1. At clinical examination a pigmented localized lesion at the lingual mandibular gingiva, non-fixed, pedunculated extends between the two interproximal 15 and 16 molars.
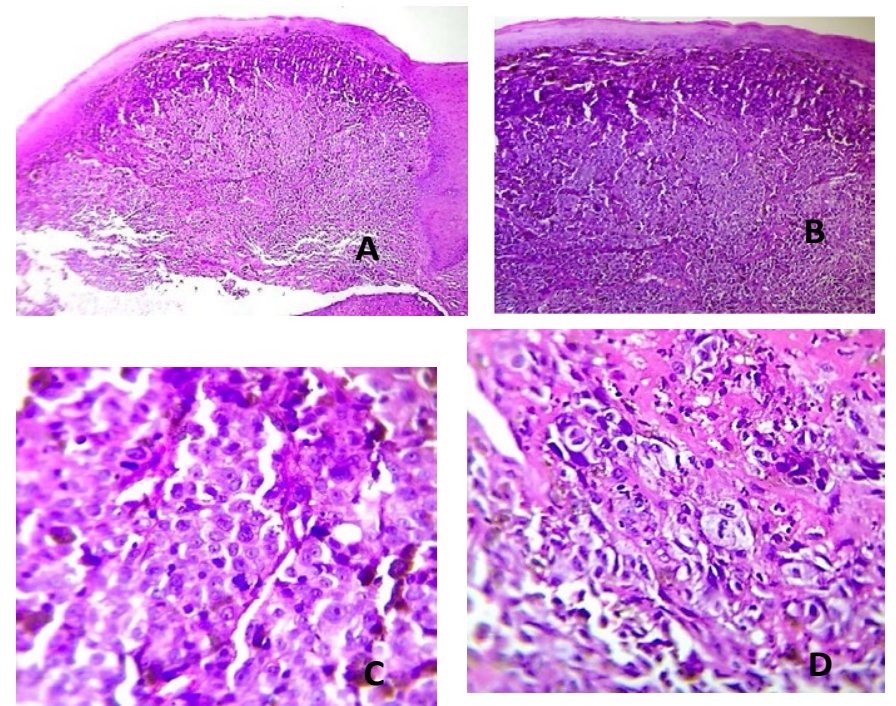

Figure 2. (A) $4 \mathrm{x}$ image nodular lesion which invade the connective tissue of the vestibular mucosa, (B) 15x epitheloid cells with inertaladed septum. (C) Atypical mitosis. (D) 40x poor symmetry with pagetoid cells.
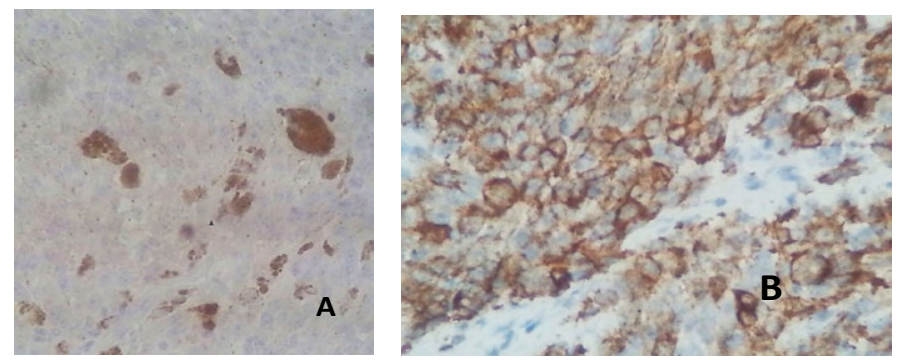

Figure 3. (A) S-100. (B). HMB-45. The histopathology report showed with atypical cells with resembled melanocites at the connective tissue, near to the epithelium were eptiheloid with atypical mitosis, and in the deeper region were spindle shaped and fusocellular component with vascular spaces, atypical mitosis, nuclear hyperchromatism, pleomorphismit was very solid, the differential was for spindle squamous cell carcinoma, and melanoma, it was solicited Cytokeratin A1-A3, S-100, HMB-45 immunohistochemistry for definitive diagnosis. The specimen was positive for S-100 and HMBB-45 leading a Melanoma Diagnosis. received radical surgery (without radiotherapy) had a better survival rate with biotherapy than without biotherapy [7-9].

Amelanotic malignant melanoma has fewer pigmented neoplastic melanocytes than other types of melanoma. It has been reported that under the influence of radiation the number of melanosomes increased, and when antiproliferative agents were added to cultured melanoma cells, the number of mature-stage melanosomes increased [20].

In the cases of the nonpigmented nodular type, these therapies were not performed but a biopsysample was undertaken, and distant metastases were found in 4 of the 5 cases. However, due to the small number of sample cases, it cannot be concluded that biopsy increases the risk of metastatic dissemination [4]. Nevertheless, judging from the present study, the patient had bleeding in some areas of the Gums, and the Periodoncist had worked on that area thinking in a Granulomatous lesion, when the lesion didn't heal, the patient was send to our department, therefore biopsy is essential to establish a definitive diagnosis for these tumors.

The patient had noticed appearance of the pigmented lesion about two months ago and it didn't seem to proliferate at a rapid rate then. Most primary oral melanomas appear as new lesions from apparently normal mucosa,the risk factor as tobacco and chronic irritation, inhaled or ingested carcinogens products at higher temperatures have been mentioned [6] whereas about $30-50 \%$ are preceded by oral pigmentations for several months or even years. The mechanism of transformation from a melanocytic nevus or pigmented macula, to OMM its difficult to known, the p53 protein alteration have been identified in two-thirds of OMMs, and the loss of heterozygosity at $12 \mathrm{p} 12$ and loss of $\mathrm{p} 27 \mathrm{~K} 1 \mathrm{P} 1$ protein expression aloud the melanoma progression [8]. Progressive loss of 5-hydroxymethylcytosine is found between benign nevi, low-grade dysplastic nevi, high-grade dysplastic nevi, atypical Spitz nevi, atypical borderline tumors, and melanoma. On average, nuclear diameter likewise increases within the spectrum of benign to dysplastic to frankly malignant melanocytic neoplasms and the loss of 5-hydroxymethylcytosine staining pattern correlates with changes in nuclear size [21]. Some of the pre-melanoma lesions include mucosal melanosis and a variety of melanocytic nevi [10-18]. Oral melanosis has been suggested as a predisposing factor for the development of oral melanoma in 30 to $73 \%$ of patients [16]. However, the incidence of melanosis in Venezuela and Colombia it is difficult to measure.

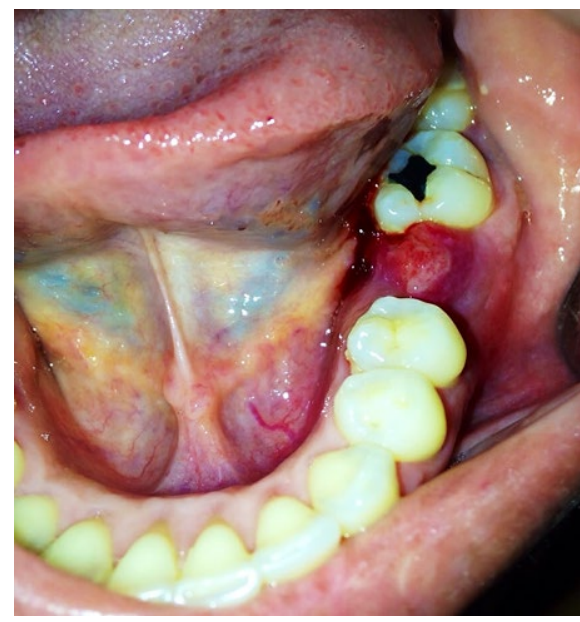

Figure 4. Picture taken, two weeks after the biopsy 
Table 1. Comparative features of nontumorigenic melanoma, dysplastic nevi, and common nevi.

\begin{tabular}{|c|c|c|c|}
\hline Feature & Melanoma & Dysplastic Nevus & Nevus \\
\hline \multicolumn{4}{|l|}{---} \\
\hline General & Larger & Intermediate & Smaller \\
\hline Size Symmetry & Poor & Good & Good \\
\hline \multicolumn{4}{|c|}{ Architectural patterns } \\
\hline Nested & Variable & Predominant & Predominant \\
\hline Nests & Coalescent & Bridging & Discrete \\
\hline Lentiginous & Continuous & Discontinuous & Discontinuous \\
\hline Pagetoid & High, extensive & Low, focal, minimal & Minimal \\
\hline Rete ridges & Irregular & Uniformly elongated & Uniform \\
\hline \multicolumn{4}{|l|}{ Cytology } \\
\hline Melanocytes & Epithelioid & Mixed & Nevoid \\
\hline Nuclear atypia & Uniform atypia & Random atypia & Minimal \\
\hline Mitoses & About $1 / 3$ of cases & Almost always absent & Absent \\
\hline \multicolumn{4}{|l|}{ Stromal responses } \\
\hline Fibroplasia & Diffuse & Concentric & Minimal \\
\hline Lymphocytes & Band-like, lichenoid & Patchy, perivascular & Minimal \\
\hline Regression & Frequent, extensive & Rare, minimal & Absent \\
\hline
\end{tabular}

Primary oral melanoma is initially asymptomatic and progresses unnoticed by patients, contributing to delay in diagnosis. Generally, recognition of the lesion occurs when there is a breakdown of the overlying epithelium or hemorrhage [16]. It is a known fact that early diagnosis and treatment of cutaneous melanomas is imperative in order to reduce mortality. If the lesions are diagnosed in an initial stage where the cancer cells are limited to the epithelium layer, it has a good prognosis [22]. The Oncology therapy of our patient was made with hemi mandibular resection with $2 \mathrm{~cm}$ extension from the prime site of the Melanoma, and level I and III Neck dissection, the Histopathology didn't report neck metastasis, so the patient is going to keep on observation.

It is important to use measures ways to project the prognosis at time of histopathological findings as Prasad et al. did proposed a microstaging system based on the extent of tumor in invaded mucosa. Level I is defined as Melanoma in situ or microinvasion, Level II as Melanoma invading up to lamina propia only and Level III as Melanoma with deep tissue invasion (skeletal muscle, bone or cartilage). The 5 -year DSS rate was $43 \%$ (median, 41.5 months). The median survival was found to decrease significantly with increasing level of invasion: Level I ( $\mathrm{n}=4)$ : 138 months; Level II $(\mathrm{n}=29)$ : 69 months; and Level III $(\mathrm{n}=28): 17$ months [19].

We, therefore, lay emphasis and. Diagnosis must be based on thorough detailed history and valid histologic evidence.

\section{Conclusions}

Oral malignant melanoma which is an extremely rare malignancy, with a rapidly invasive onset, are silent and asymptomatic tumor, Clinically in their appearance, promote misleading, because is not the first presumptive diagnosis on evaluation, and almost always the first oral health professional didn't look carefully for a biopsy, that's why the importance of early detection and diagnosis which can be lifesaving cannot be overemphasized. We reiterate on the importance of maintaining a high index of suspicion and early detection and diagnosis for any pigmented lesions, especially if they occur in highrisk sites like the palate or gingiva.

\section{Conflicts of interest}

None conflicts of interest declare.

\section{Acknowledgments}

This paper was made with personal resources, any Institution use financial help for this. The patient sign all the documents for being part of this paper, her name is Y.B, in her history number 1578 is all the signed permission.

\section{References}

1. Parkin DM,Bray F, Ferlay J,Pisani P (2005) Global cancer statistics, 2002. Ca-A Cancer Journal for Clinicians 55:74-108. [Crossref]

2. Umeda M, Komatsubara H, Shibuya Y, Yokoo S, Komori T (2002) Premalignant melanocytic dysplasia and malignant melanoma of the oral mucosa. Oral Oncol 38: 714-722. [Crossref]

3. Umeda M, Mishima Y, Teranobu O, Nakanishi K, Shimada K (1988) Heterogeneity of primary malignant melanomas in oral mucosa: an analysis of 43 cases in Japan. Pathology 20: 234-241. [Crossref]

4. Saku T, Takahashi H, Okabe H, Tsuda N, Okumura H,et al. (1983) Oral amelanotic melanoma - report of a casewith desmoplastic changes at the site of lymph node metastasis. Gan No Rinsho 29: 424-432. [Crossref]

5. McLaughlin CC, Wu XC, Jemal A, Martin HJ, Roche LM, et al. (2005) Incidence of noncutaneous melanomas in the US. Cancer 103: 1000-1007. [Crossref] 
6. Sortino-Rachou AM, CancelaMde V, Voti L, Curado MP (2008) Primary oral melanoma: population-based incidence. Oral Oncol 44: 1039-1046. [Crossref]

7. Sun CZ1, Chen YF, Jiang YE, Hu ZD, Yang AK,et al. (2012) Treatment and prognosis of oral mucosal melanoma. Oral Oncology 48: 647-652. [Crossref]

8. Mucke T, Holzle F, Kesting MR, Loeffelbein DJ, Robitzky LK, et al. (2009) Tumor size and depth in primary malignant melanoma in the oral cavity influences survival. $J$ Oral Maxillofac Surg 67: 1409-1415. [Crossref]

9. Meleti M, Leemans CR, Mooi WJ, Vescovi P, van der Waal IC (2007) Oral Malignant melanoma: a review of the Literature. Oral Oncol 43: 116-121.

10. Tanaka N, Mimura M, Kimijima Y, Amagasa T (2004) Clinical investigation of amelanotic malignant melanoma in the oral region. J Oral Maxillofac Surg 62: 933937. [Crossref]

11. Ducic Y, Pulsipher DA (2001)Amelanotic melanoma of the palate: report of a case. $J$ Oral Maxillofac Surg 59: 580-583. [Crossref]

12. Kuwazawa T, Okamoto T, Yamamura T, Ogiuchi Y, Uchiyama H, et al. (2001) A case of the multiple primary cancer involving maxillary amelanotic malignant melanoma and gastric cancer. Jpn J Oral Maxillofac Surg 47: 243-246.

13. Katsuno M, Kubota T, Matsui K, Takasaki S, Kobayashi S, et al. (2001) A case of amelanotic malignant melanoma in the hard palatal mucosa successfully treated with intra-tumoral injection of interferon. Stomato-pharyngol 13: 203-207.

14. Notani K, Shindoh M, Yamazaki Y, Nakamura H, Watanabe M,et al. (2002) Amelanotic malignant melanomas of the oral mucosa. Br J Oral Maxillofac Surg 40: 195-200. [Crossref]
15. 15.Tanaka N, Mimura M, Ogi K, Amagasa T (2004) Primary malignant melanoma of the oral cavity: assessment of outcome from the clinical records of 35 patients. Int $J$ Oral Maxillofac Surg 33: 761-765. [Crossref]

16. Umeda M, Komatsubara H, Shigeta T, Ojima Y, Minamkawa T, et al. (2008) Treatmen and prognosis of malignant melanoma of the oral cavity: preoperative surgical procedure increases risk of distant metástasis. Oral Surg Oral Med Oral Pathol Oral Radiol Endod 106: 51-57. [Crossref]

17. Stephen E, David Byrd, Carolyn C, April F, et al. (2010) Mucosal melanoma of the head and neck. (7thedn), New York: Springer Science, Business Media LLC97-100.

18. Mohan M, Vihang S, Deepak P, Smitha B (2013) Oral malignant melanoma: systematic review of the literature and report of two cases. Oral Surg Oral Med Oral Pathol Oral Radiol 116: e247-e254. [Crossref]

19. Prasad ML, Patel SG, Huvos AG, Shah JP, Busam KJ (2004) Primary mucosa melanoma of the head and neck: a proposal for microstaging localized, Stage I (lymph node-negative) tumors. Cancer 100: 1657-1664. [Crossref]

20. Mimura M, Tanaka N, Eishi Y, Kimijima Y, Amagasa T, et al. (1997) An ultrastructural study of the influence of radiation against cell line derived from human oral malignant melanoma. Med Electron Microsc 30: 81

21. Larson AR, Dresser KA, Zhan Q, Lezcano C, Woda BA,et al. Loss of 5-hydroxymethylcytosine correlates with increasing morphologic dysplasia in melanocytic tumors. Mod Pathol 27: 936-944. [Crossref]

22. Moreno MA, Hanna EY (2010) Management of mucosal Melanomas of the Head and Neck: did we make any progress? Curr Opin Otolaryngol Head Neck Surg18: 101-106. [Crossref]

Copyright: $(02015$ Alberto PL. This is an open-access article distributed under the terms of the Creative Commons Attribution License, which permits unrestricted use, distribution, and reproduction in any medium, provided the original author and source are credited. 